\title{
A LIBERDADE RELIGIOSA E CONSTITUIÇÕES DO BRASIL: reflexões sobre o espaço das religiões de matriz afro-brasileira ante a tradição e jurisprudência nacionais
}

\author{
Otávio Barduzzi Rodrigues da Costa \\ Universidade Anhanguera \\ E-mail: joebarduzzi@yahoo.com.br \\ Luiz Fernando de Lima Ribeiro \\ Universidade Estadual Paulista (UNESP) \\ E-mail: luizfernando.direito@hotmail.com \\ Roberta Cava \\ Universidade Estadual Paulista (UNESP) \\ E-mail: roberta_cava@yahoo.com.br
}

\begin{abstract}
RESUMO
O presente trabalho tem por objetivo fundamental estudar as religiões de matriz afro-brasileira (RMAB), tomando por hipótese que, a despeito da laicidade estatal determinada pelas Constituições que vigoraram no Brasil, à exceção da primeira, o histórico de formação do Estado brasileiro, suas tradições e episódios protagonizados pelo Poder Judiciário do país não apenas dificultam, mas também tolhem o espaço devido às RMAB nas dinâmicas social, cultural, política e educacional do Brasil. Para tanto, a pesquisa trata, inicialmente, da compreensão da influência católica na construção do país e, posteriormente, nos textos constitucionais que já vigoraram e o atual, abordando também a aplicação do conceito de laicidade. Em seguida, dedica-se espaço a reflexões sobre conceitos como alteridade, liberdade e tolerância, bem como sobre o sincretismo advindo da chegada dos escravos africanos ao Brasil. Adiante, discute-se a respeito do reconhecimento legal da diversidade cultural brasileira em virtude da herança indígena e africana do país para, por fim, analisar a postura do processo legislativo no que tange a essa diversidade. A título de problematização e reflexão crítica, o trabalho apresenta três casos distintos, em que a jurisprudência brasileira se depara com cenários de intolerância contra as RMAB, sendo conduzidas de maneiras distintas.
\end{abstract}

Palavras-chave: Religiões de matriz afro-brasileira. Laicidade. Constituições brasileiras. Liberdade religiosa. Jurisprudência Brasileira.

\section{THE RELIGIOUS FREEDOM AND CONSTITUTIONS OF BRAZIL: reflections on the space of Afro-Brazilian matrix religions to national tradition and jurisprudence}

\begin{abstract}
The main objective of this study is to study Afro-Brazilian religions (RMAB), assuming that, in spite of the state secularity determined by the Brazilian Constitutions, with the exception of the first, the history of formation of the Brazilian State, its traditions and episodes carried out by the country's Judiciary not only hinder but also block the space due to RMAB in the social, cultural, political and educational dynamics of Brazil. In order to do so, the research initially deals with the understanding of the Catholic influence in the construction of the country and, later, in the constitutional texts that have already been in force and the current one, also addressing the application of the concept of secularity. Afterwards, there is space for reflections on concepts such as alterity, freedom and tolerance, as well as on the syncretism coming from the arrival of the
\end{abstract}


African slaves to Brazil. Later, we discuss about the legal recognition of Brazilian cultural diversity due to the country's indigenous and African heritage, in order to analyze the position of the legislative process regarding this diversity. As a matter of problematization and critical reflection, the work presents three distinct cases, in which Brazilian jurisprudence is faced with scenarios of intolerance against RMAB, being conducted in different ways.

Keywords: Afro-Brazilian religions. Laicity. Brazilian Constitutions. Religious freedom. Brazilian Jurisprudence. 


\section{INTRODUÇÃO}

O presente trabalho toma como objeto de estudo a liberdade religiosa no Brasil, à luz da legislação do país, estabelecendo como recorte o âmbito das Religiões de Matriz Afro-Brasileira, abreviadamente conhecida por RMAB.

A colonização portuguesa utilizou como instrumento fundamental para o processo colonizador a Igreja Católica, responsável, ao longo desse processo, pela catequização indígena e, posteriormente, a dos negros africanos. Esse cenário deu origem a um sincretismo religioso, dada a articulação das diferentes culturas, valores e costumes.

Entretanto, as RMAB são, frequentemente, alvo de discriminação social e hostilidade, bem como dificuldades institucionais. Nesse sentido, o trabalho tem por objetivo geral uma reflexão acerca dos obstáculos a uma liberdade religiosa plena, considerando o cenário de discriminação em geral dispensado às RMAB.

Liberdade religiosa pode ser definida como a condição plena, desde que não proibida pela lei, de expressar sua espiritualidade em toda sua plenitude (OAB-SP, 2010). Entretanto, apesar de sua presença profunda da cultura e história brasileira, em termos jurídicos, a efetividade da expressão das RMAB não alcança a devida plenitude no tocante à expectativa constitucional de liberdade religiosa.

A República Federativa do Brasil tem expressa, em sua Carta Magna, a condição de Estado laico. Nesse sentido, nenhuma vertente religiosa deveria se sobrepor em nenhum aspecto da estrutura social, política e econômica do país, seja em termos institucionais, comportamentais, culturais e legais. Todavia, é possível observar a influência significativa de religiões de matriz cristã em âmbitos diversos da dinâmica do Estado brasileiro. Datas católicas, por exemplo, são destacadas como feriados nacionais. Líderes religiosos católicos e evangélicos têm tratamento diferenciado no que se refere à sua condição de líderes. Ainda, número considerável de legisladores também aplicam valores católicos e evangélicos quando da condução da atividade legislativa do país.

Em clara oposição, cidadãos que professam fé relacionada às RMAB, bem como seus líderes, são frequentemente alvo de discriminação, violência, hostilidades e dificuldades institucionais, que ganham evidência quando comparadas com o cenário exposto acima.

Nesse sentido, o artigo apresenta como problemática o contexto de preconceito e desigualdade no qual as RMAB estão inseridas. Em particular, destaca como problema específico o fato de o Brasil ser um país laico, mas que, de maneira significativa, insere valores cristãos, 
especialmente de origem católica e evangélica em sua dinâmica política, econômica e social, incentivando, então, um cenário de "primazia" dessas religiões perante as religiões afro-brasileiras.

A justificativa para a condução da presente pesquisa recai, primordialmente, na percepção de que sem liberdade, inclusive a liberdade religiosa, não há democracia. Faz-se necessário, então, um estudo que refletir acerca do resguardo desse direito, de modo a contribuir para discussões fundamentadas com vistas a maior verificação do respeito e igualdade a todas as religiões, em particular as de origem afro, objeto deste trabalho. Tal estudo também é relevante no sentido de contribuir para ações e políticas contra a discriminação, preservando a liberdade de culto em todas as suas manifestações.

\section{A RELIGIÃO E O ESTADO BRASILEIRO}

A história do Brasil é marcada pela religiosidade desde o descobrimento do país. A forte influência da Igreja Católica Romana se faz presente desde o nome atribuído ao território descoberto pelos portugueses em 1500: "Ilha de Vera Cruz" e, posteriormente, "Terra de Santa Cruz".

De fato, o caminho percorrido pelas religiões até a liberdade religiosa e de culto amparada por lei atualmente é herança da grande presença da fé católica, estando presente nas sete Constituições já adotadas pelo Brasil: 1824, 1891, 1934, 1937, 1946, 1967 e 1988. Para a compreensão dessa presença marcante do catolicismo, faz-se necessário compreender como se deu a inserção dessa crença na realidade brasileira.

Durante a colonização do Brasil, o Estado português priorizou a estruturação da economia e administração do novo território, ficando a cargo da Igreja Católica a orientação educacional, cultural e religiosa dos nativos e colonos (FAUSTO, 1996, p. 16). Toma-se como referencial dessa estratégia a chegada de Tomé de Souza e Manuel da Nóbrega à Bahia, em 1549, alto funcionário da Coroa portuguesa, que assumiu o cargo de primeiro governador geral. Foi fundador da cidade de Salvador, tendo combatido e destruído aldeias Tupinambás para assentar populações (FAUSTO, 1996, pp. 20-26).

A Igreja Católica foi fundamental no processo de articulação cultural e educacional no novo território, atuando como um forte agente colonizador. Religiosos como o Padre Anchieta, por exemplo, viabilizaram uma língua geral para a catequização, traduzindo a evangelização católica a partir da língua Tupi (FAUSTO, 1996, pp. 55-57). A esse respeito, os jesuítas, "para atrair crianças indígenas buscaram trazer meninos órfãos de Lisboa para fazerem a ligação com os curumins [...] 
faziam-no representar autos, mistérios, de fundo e sabor medieval, para depois chamá-los às missões, às escolas, aos colégios (RIOS, 1994, p. 22). Além disso, também articularam a noção de culto a um único deus aos indígenas, relacionando o deus indígena Tupã, detentor do poder dos trovões, ao deus católico.

Entretanto, essa dinâmica estabelecida para que o catolicismo prevalecesse sobre a cultura indígena envolvia uma negação do "outro", do "diferente", no sentido de que a os elementos indígenas deveriam ser diluídos em favor da fé cristã. Com efeito, os jesuítas estabeleceram o pressuposto de que a as almas dos índios eram inconsistentes, dada a falta de um sistema religioso ordenado, tal qual o católico (CASTRO, 2002, pp. 218-219). Por conseguinte, não havia também centralidade política, o que favoreceu a investida dos jesuítas na catequização dos nativos.

Dessa forma, foi possível progredir por meio de uma inserção de novos símbolos e ao mesmo tempo desvalorização dos já existentes, o que consistiu em um aprofundamento da estratégia de dissolução da cultura nativa:

\footnotetext{
Os jesuítas introduziram conceitos e vocábulos novos na religiosidade indígena, empregando estratégias para desmerecer os pajés, considerando-se eles mesmos como os verdadeiros. Reinterpretaram a mitologia indígena, incorporando seus heróis à crença cristã. Como exemplo, introduziram a figura do anjo, elemento inexistente entre os tupis (MACEDO, 2008, p. 8).
}

Ao mesmo tempo, além da catequização dos indígenas, a Igreja Católica também foi instrumento importante na escravidão africana que, posteriormente, tomou lugar no Brasil. A justificativa adotada foi a de que trazer os negros da África para a colônia brasileira era uma forma de a Divina Providência "salvar suas almas e afastá-los do pecado", por meio da palavra de Deus (FAUSTO, 1996, p. 30).

É necessário ressaltar aqui que a fé católica enquanto instrumento colonização e consolidação do poder europeu no Brasil continua evidente durante o período de escravidão no país, configurando-se como um catolicismo "patriarcal”, assentado na dinâmica dos engenhos de canade-açúcar durante os séculos XVI e XVII (FAUSTO, 1996, p. 47). Nesse cenário, tratado extensamente por Gilberto Freyre em "Casa Grande e Senzala", o caráter patriarcal do catolicismo está amparado nas fazendas dos senhores de engenho, que forçavam seus escravos a professar o catolicismo, difundido pelas capelas locais. Configura-se, portanto, um espaço de poder particular no interior das propriedades, sustentado ao mesmo tempo pela religião e pela produção e comércio da cana (FREYRE, 1992).

Assim, o trabalho evangelizador promovido pela Igreja, atrelado à responsabilidade pela educação religiosa, linguística e cultural, permitiu à Coroa portuguesa alcançar um determinado 
grau de homogeneidade social que abriria caminho para a declaração da independência do Brasil em 1822, deixando uma herança que se faz presente nas Constituições do novo país, como tratado a seguir.

\section{A LIBERDADE RELIGIOSA NAS CONSTITUIÇÕES DO BRASIL}

O presente momento do trabalho de dedica a analisar a presença da temática da religião nas constituições já vigentes na história do Brasil, de modo a refletir a respeito da inserção normativa da percepção de liberdade religiosa na dinâmica social brasileira, e também do alcance do controle de constitucionalidade ao qual a religião está submetida.

Desde a sua independência até os dias de hoje, o Brasil teve sete Constituições, cada uma refletindo o contexto histórico em que foram elaboradas. Em particular, a relação entre o Estado e a Igreja sofreu várias alterações ao longo do tempo, refletindo de várias maneiras no campo do Direito. Dessa forma, a liberdade religiosa foi contemplada em amplitudes diversas, dependendo do momento histórico em que era discutida.

A constituição de 1824 é a única Constituição que estabelece uma religião oficial do país, a Católica Apostólica Romana. Entretanto, também previa liberdade de culto para todas as crenças, porém somente em âmbito doméstico. Em termos de participação política, a Carta de 1824 restringia o direito de votar e ser votado às classes mais abastadas, mas também contemplava a existência dos "libertos", escravos alforriados. É a Carta que permaneceu em vigor por mais tempo, 65 anos.

Entretanto, apesar dessas restrições, a Carta de 1824 é tida como moderna, no sentido de romper com as premissas absolutistas ainda evidentes na Europa, e permitiu a inserção de um sistema constitucional, ainda que deficiente, que normatizava alguns direitos fundamentais como a “inviolabilidade dos direitos civis e políticos, o conceito de cidadania, a liberdade de expressão e de religião, entre outras garantias, o que se revelou um avanço para a época, em se tratando de uma Constituição elaborada na América do Sul” (VAINER, 2010, p. 163). 
A constituição de 1891 No que diz respeito à relação entre Estado e religião, a Constituição estabelecia, em seu artigo $7^{\circ}$, que "nenhum culto ou igreja gozará de subvenção oficial, nem terá relações de dependência ou aliança com o Governo da União ou dos Estados". Já no tocante à liberdade religiosa, o artigo 10 previa que não poderia o Estado "estabelecer, subvencionar, ou embaraçar o exercício de cultos religiosos" e, em seu artigo $72, \S 3^{\circ}$, estipulava-se que "todos os indivíduos e confissões religiosas podem exercer pública e livremente o seu culto, associando-se para esse fim e adquirindo bens, observadas as disposições do direito comum" (CONSTITUIÇÃO DA REPÚBLICA DOS ESTADOS UNIDOS DO BRASIL, 1891). Estava a ideia do estado laico a qual se seguiram todas as outras.

Em 5 de outubro de 1988, foi promulgada a nova Constituição, que, originalmente, apresentava um regime parlamentarista. Posteriormente, com a influência do presidente Sarney e de alguns parlamentares, o regime adotado foi o presidencialismo.

A atual Constituição, que em seu preâmbulo também atesta a "proteção de Deus", ao tratar dos direitos e deveres individuais e coletivos, atesta a inviolabilidade da "liberdade de consciência e de crença, sendo assegurado o livre exercício dos cultos religiosos e garantida, na forma da lei, a proteção aos locais de culto e suas liturgias" (CONSTITUIÇÃO DA REPÚBLICA FEDERATIVA DO BRASIL, 1988, art. 5 , inciso VI).

Mantém, ainda, a proibição a "relações de aliança e dependência com cultos religiosos ou igrejas, ressalvada, na forma da lei, na forma da lei, a colaboração de interesse público" (CONSTITUIÇÃO DA REPÚBLICA FEDERATIVA DO BRASIL, 1988, art. 19, inciso I).

Entretanto, muitos são os obstáculos que se apresentam à observação plena da liberdade religiosa no Brasil, que é a hipótese central do trabalho. Dessa forma, a seguir, a pesquisa tratará da laicidade do Estado brasileiro, bem como das noções de tolerância e liberdade, para permitir a reflexão a que o trabalho se dedica.

\section{A LAICIDADE DO ESTADO BRASILEIRO}

A discussão acerca do caráter laico no Estado brasileiro pede, de antemão, a conceitualização do termo "laicidade".

Destaca-se aqui, então, a percepção de Aloísio Santos Júnior (2007, pp. 62-63):

A laicidade do Estado se mostra de duas formas distintas. A primeira delas, muito comum nos estados seculares europeus é a não intervenção drástica do Estado na Religião. É a separação total, que tende a restringir a religião ao foro íntimo de cada cidadão, impedindo qualquer manifestação religiosa em espaços públicos. Outro modelo é aquele adotado no Brasil, que, apesar da separação total entre o Estado e a religião, vê nesta, uma forma de 
integração social, permitindo assim, manifestações religiosas em espaços públicos, garantindo sua ocorrência de diversas formas.

Tendo em conta o excerto acima, pode-se tomar a laicidade, via de regra, como um tipo de organização em que as questões religiosas e estatais permanecem em âmbitos distintos, e não interligados. É possível tratar dessa organização de maneira a manter as manifestações religiosas na esfera privada da vida do indivíduo, ou ainda perceber a religião como um elemento pertencente à dinâmica de uma sociedade, permitindo, portanto, o seu tratamento de maneira pública, como acontece no Brasil e na maior parte dos Estados.

Entretanto, a laicidade é frequentemente tomada como sinônimo de "laicismo". Com efeito, trata-se de conceitos diferentes, sendo necessário, assim, também conceituar este último:

O laicismo é um sistema jurídico-político no qual há separação total entre o Estado e a Religião. Neste sistema, Estado e organizações religiosas não sofrem interferências recíprocas no exercício de suas atividades. Por outro lado, laicidade é o caráter de neutralidade religiosa do Estado (SANTOS JR, 2007, p. 62).

Pode-se inferir, portanto, que enquanto a laicidade se caracteriza como um padrão organizacional referente à expressão de valores religiosos autônomos em relação ao Estado, o laicismo normatiza essa percepção, tornando-a parte fundamental da estrutura de um Estado e, por conseguinte, de suas instituições e sociedade.

O laicismo foi adotado no Brasil quando da instauração da República, legitimada por meio do decreto 119-A, de 1890, de modo que

O Estado Brasileiro tornou-se desde então laico, ou não confessional. Isto significa que ele se mantém indiferente às diversas igrejas que podem livremente constituir-se, para o que o direito presta a sua ajuda pelo conferimento do recurso à personalidade jurídica (BASTOS, 2002, p. 336).

Sendo o Brasil um Estado laico, ao mesmo tempo em que as religiões, independentemente do rótulo, podem interferir na atividade estatal, tampouco o Estado tem a premissa de ignorar a existência das religiões e sua presença na dinâmica social e política do país. Assim, há que se observar que o Estado laico não torna um ou outro rótulo religioso como oficial, mas também não oficializa a não existência das religiões. Deve, portanto, garantir que tanto aqueles que professam uma crença, e sua manifestação, quanto aqueles que não o fazem, sejam tratados igualmente.

Mais além, ao se considerar a observação de Aloisio Santos Jr acerca dos dois modelos possíveis de laicidade, há que se considerar que, havendo países em que a manifestação pública dos valores religiosos é permitida e em outros não, é possível inferir que a maneira como a laicidade é 
tratada em determinado Estado, e portanto a sua percepção em enquanto laicismo, está atrelada à soberania de um país e à conformação da sua estrutura de poder.

Aqui, é possível retomar a organização dos Estados absolutistas, em que os monarcas se legitimavam enquanto líderes absolutos por meio da religião, apresentando-se como representações divinas na Terra. Entretanto, o advento do pensamento Iluminista a partir do século XVIII e sua racionalidade característica forçou uma reflexão acerca dessa ótica, que não mais se sustentava. Dessa forma, abriu-se espaço para o surgimento da teoria do poder constituinte (BONAVIDES, 2009, p. 143), por meio da qual os indivíduos passam a ser tomados enquanto cidadãos, portadores de direitos, que são governados por meio de representantes comprometidos com a vontade geral (ROUSSEAU, 2003, p. 14).

Observa-se, então, que a condição da laicidade se atrela à soberania de um Estado no sentido de que a liderança e condução da vida do país não mais estão ligadas a premissas religiosas, agora substituídas pela teoria do poder constituinte. A respeito dessa transição, Bonavides salienta que:

\footnotetext{
Com as monarquias absolutistas a titularidade veio a recair no monarca, que a justificava mediante a invocação de um suposto direito. Durante a Revolução Francesa o mesmo poder coube nominalmente à Nação ou ao povo, mas de modo efetivo, no seu exercício, a uma Classe - a burguesia - ou seja, aquela parte do povo que toma "consciência política autônoma" e entra a decidir acerca da forma de existência estatal, exercendo, por consequência o poder constituinte (BONAVIDES, 2009, p. 158).
}

Dessa forma, é possível inferir que a laicidade do Estado está diretamente relacionada à ascensão dos ideais iluministas, cuja ênfase recaía sobre a racionalidade, e que essa mudança de perspectiva abriu espaço para ordenamentos constitucionais mais organizados, que incluem a garantia dos direitos fundamentais e respeito às liberdades individuais, elementos que são determinantes para o objetivo dessa pesquisa.

Com efeito, na esteira desse raciocínio, a etapa a seguir tratará da questão da tolerância e liberdade, conceitos valorizados pela laicidade do Estado, e igualmente fundamentais para o presente trabalho.

\section{TOLERÂNCIA, LIBERDADE E ALTERIDADE E A LIBERDADE RELIGIOSA}

O cenário sociopolítico que a laicidade do Estado permitiu é extremamente relevante para a reflexão acerca da liberdade religiosa, haja vista o respeito às individualidades, inclusive no âmbito religioso, estarem respaldadas pela lógica de não-intervenção entre Estado e Igreja. 
Aqui, é válido destacar que a laicidade

Salvaguarda as diversas confissões religiosas do risco de intervenções abusivas do Estado nas suas questões internas, concernentes a aspectos como os valores e doutrinas professados, a forma de cultuá-los, a sua organização institucional, os seus processos de tomada de decisões, a forma e o critério de seleção dos seus sacerdotes e membros, etc. [...] A laicidade também protege o Estado de influências indevidas provenientes da seara religiosa, impedindo todo o tipo de confusão entre o poder secular democrático, em que estão investidas as autoridades públicas, e qualquer confissão religiosa, inclusive a majoritária (SARMENTO, 2008, p. 190).

Nesse sentido, conceitos como igualdade, liberdade e tolerância devem ser considerados e analisados, para que a reflexão acerca da liberdade religiosa seja adequada.

De fato, a premissa de liberdade religiosa exige a observação na noção de liberdade. Tratase de um conceito de caráter essencialmente filosófico, mas que permite diversas leituras. Uma leitura possível é a apresentada pelo cientista político italiano Norberto Bobbio, que subdivide a liberdade em negativa e positiva.

Para esse teórico, a liberdade negativa é "a situação na qual um sujeito tem a possibilidade de agir sem ser impedido, ou de não agir sem ser obrigado, por outros sujeitos" (BOBBIO, 2002, p. 48). Com isso, garante-se ao indivíduo a possibilidade de realizar aquilo que deseja, e, ao mesmo tempo, não se pode força-lo a fazer aquilo que não deseja.

A liberdade positiva, por sua vez, é conceituada pelo estudioso italiano como uma "situação na qual um sujeito tem a possibilidade de orientar seu próprio querer no sentido de uma finalidade, de tomar decisões, sem ser determinado pelo querer de outros. Essa forma de liberdade é também chamada de autodeterminação ou, ainda mais propriamente, de autonomia" (BOBBIO, 2002, p. 51). Aqui, trata-se do agir individual autônomo, qual seja, aquele que não é determinado ou forçado por valores ou elementos externos, diferentes daqueles do próprio indivíduo.

Com efeito, essa percepção está expressa na Declaração dos Direitos do Homem e do Cidadão, documento originado da Revolução Francesa, em 1789:

A liberdade consiste em poder fazer tudo o que não prejudique a outrem: assim, o exercício dos direitos naturais do homem não tem outros limites senão os que asseguram aos demais membros da sociedade o gozo dos mesmos direitos. Esses limites somente a lei pode determinar (DECLARAÇÃO DOS DIREITOS DO HOMEM E DO CIDADÃO, 1789).

Há que se considerar que essa percepção de liberdade reflete as angústias do cenário francês à época; entretanto, a sua essência continua ao longo do tempo, sendo considerada um dos fundamentos do Estado Democrático de Direito, juntamente com o conceito de igualdade.

No que diz respeito à igualdade, trata-se de um conceito sobre o qual se assenta a essência do Estado social. A esse respeito, vale apontar que 
O centro medular do Estado social e de todos os direitos de sua ordem jurídica é indubitavelmente o princípio da igualdade. Com efeito, materializa ele a liberdade da herança clássica, e com esta compõe um eixo ao redor do qual gira toda a concepção estrutural do Estado democrático contemporâneo (BONAVIDES, 2009, p.376).

Com efeito, é a partir da noção de igualdade que os demais princípios que compõe a democracia e o estado social podem inseridos: "a igualdade constitui o signo fundamental da democracia" (SILVA, 2007, p. 11), sendo considerada também “o mais vasto dos princípios constitucionais, não se vendo recanto onde ela não seja impositiva" (BASTOS, 2002, p. 323).

Assim como o conceito de liberdade, que Norberto Bobbio dividiu em duas percepções, também o conceito de igualdade pode ser subdividido. Celso Ribeiro de Bastos explana sobre as duas percepções de igualdade:

A igualdade substancial postula o tratamento uniforme de todos os homens. Não se trata, como se vê, de um tratamento igual perante o direito, mas de uma igualdade real e efetiva perante os bens da vida. [...] A igualdade formal ensina consiste no direito de todo cidadão não ser desigualado pela lei senão em consonância com os critérios albergados ou ao menos não vedados pelo ordenamento constitucional (BASTOS, 2002, p. 317).

É possível também refletir a respeito da igualdade em termos mais amplos e gerais. Aqui, é possível recorrer a Hans Kelsen, para quem é fundamental se ter em conta a noção de diferença, de modo que a igualdade ou isonomia possam ser garantidas. Nesse sentido,

A igualdade dos sujeitos na ordenação jurídica, garantida pela Constituição [brasileira], não significa que estes devam ser tratados de maneira idêntica nas normas e em particular nas leis expedidas com base na Constituição. A igualdade assim entendida não é concebível: seria absurdo impor a todos os indivíduos exatamente as mesmas obrigações ou lhes conferir exatamente os mesmos direitos sem fazer distinção alguma entre eles, como, por exemplo, entre crianças e adultos, indivíduos mentalmente sadios e alienados, homens e mulheres. (KELSEN apud MELLO, 2006 p.23).

De fato, percebe-se que o princípio de igualdade preconizado em 1789 durante a Revolução Francesa foi apropriado de maneiras distintas, sendo uma delas a proposta do princípio de isonomia, fundamental para o Estado Democrático de Direito, por ser capaz de

Vedar que a lei enlace uma consequência a um fato que não justifica tal ligação. É o caso do racismo em que a ordem jurídica passa a perseguir determinada raça minoritária, unicamente por preconceito das classes majoritárias. Na mesma linha das raças, encontramse o sexo, as crenças religiosas, ideológicas ou políticas, enfim, uma série de fatores que os próprios textos constitucionais se incumbem de tornar proibidos de diferenciação. É dizer, não pode haver uma lei que discrimine em função desses critérios. (BASTOS, 2002, p.321). 
Ante o exposto, é possível afirmar que tanto liberdade quanto igualdade são cruciais para as premissas democráticas. Tendo como referência a Constituição Brasileira de 1988, ambos os conceitos estão expressos já em seu preâmbulo:

\begin{abstract}
Nós, representantes do povo brasileiro, reunidos em Assembleia Nacional Constituinte para instituir um Estado Democrático, destinado a assegurar o exercício dos direitos sociais e individuais, a liberdade, a segurança, o bem-estar, o desenvolvimento, a igualdade e a justiça como valores supremos de uma sociedade fraterna, pluralista e sem preconceitos, fundada na harmonia social e comprometida, na ordem interna e internacional, com a solução pacífica das controvérsias, promulgamos, sob a proteção de Deus, a seguinte Constituição da República Federativa do Brasil. (CONSTITUIÇÃO DA REPÚBLICA FEDERATIVA DO BRASIL, 1988).
\end{abstract}

Tendo em conta as explanações acerca dos conceitos de liberdade e igualdade, bem como a relação intrínseca entre eles, faz-se necessário, finalmente, discorrer acerca da tolerância e alteridade, a fim de melhor refletir a respeito da liberdade religiosa.

A noção de tolerância tem uma herança religiosa, que é evidenciada também no período iluminista, no século XVIII. Com efeito, Voltaire, em sua obra "Tratado sobre a Tolerância", sustenta que tolerância no âmbito da religião foi um dos elementos mais fortes da história antiga, apontando que, em geral, gregos, romanos e judeus toleravam crenças diferentes (VOLTAIRE, 2008, pp. 40-47). Mais além, a permissão dada pelo Imperador Constantino à liberdade de crença aos cristãos, ao fim do Império Romano, reforça a percepção de que a noção de tolerância remete à temática da religião.

Em termos contemporâneos, a Declaração de Independência dos EUA, de 1776, e a Declaração dos Direitos do Homem e do Cidadão, de 1789, resultado da Revolução Francesa, também fazem menção à tolerância. Nota-se, portanto, que a concepção de tolerância surgiu do combate à intolerância, inicialmente religiosa, mas depois difundida para as questões de raça, classe social, etnias, etc. Trata-se, então, de garantir espaço para a diversidade em um mesmo local.

Assim, a fim de conceituar a tolerância, vale ressaltar que esta é

Uma reação contra uma situação dada: contra a intolerância nascida do etnocentrismo, da rejeição do outro. A tolerância é uma negação da negação, suscitada pela indignação frente à intolerância; é a defesa de um direito humano dos mais sagrados: o direito à diferença. Equivale a declarar que o intolerável mesmo é a intolerância. É uma reafirmação, uma reposição do sujeito frente à intolerância que quer negá-lo; ao afirmar-se contra sua negação, afirma-se como um direito de ser o que é; e nega ao intolerante o direito de negálo (MENESES, 1996, p. 6).

Destacando o direito à diferença apontado no trecho acima, é possível articular à percepção de tolerância a noção de alteridade. Em sua abordagem filosófica, a alteridade pode ser 
compreendida como "ser outro, colocar-se ou constituir-se como outro" (ABBAGNANO, 1998, p. 34-35).

Nesse sentido, a alteridade, assim como a tolerância, percebe a existência do "diferente", mas, para além do convívio com a diferença, a alteridade envolve essencialmente o reconhecimento da diversidade enquanto legítimo e parte integrante da dinâmica social em que o indivíduo se insere.

Evidentemente, o reconhecimento do "outro" não necessariamente implica uma percepção positiva deste; é comum, ao longo da história, a prática da alteridade em sentido negativo, em que se reconhece o "outro", o "diferente", mas, ao invés de tolerá-lo, ocorre a sua dissolução, como no caso das colonizações espanholas na América, que aniquilaram as culturas maia e asteca, e também a colonização portuguesa no Brasil, como exposto anteriormente, que procurou sobrepor a crença cristã católica à cultura dos nativos.

Uma vez feita a reflexão acerca dos conceitos de igualdade, liberdade, tolerância e alteridade, faz-se possível analisá-los sob a ótica da liberdade religiosa.

A liberdade religiosa é uma expansão da noção de liberdade em sentido amplo. De fato, a liberdade religiosa deriva diretamente da liberdade de pensamento, expressa no artigo 18 da Declaração Universal dos Direitos Humanos, de 1948.

A liberdade de crença está expressa no artigo $5^{\circ}$, inciso VI, da Constituição de 1988: "é inviolável a liberdade de consciência e de crença, sendo assegurado o livre exercício dos cultos religiosos e garantida, na forma da lei, a proteção aos locais de culto e a suas liturgias". Trata-se de uma inovação em comparação à Emenda Constitucional $n^{\circ} 1$, de 1969 , que previa somente a liberdade de consciência e o livre exercício de cultos religiosos, não estando explícita, portanto, a liberdade religiosa.

De acordo com o texto de 1988, está assegurada, então, a livre escolha por uma religião ou crença, independente do seu rótulo, uma vez que diz respeito íntimo dos indivíduos, não sendo possível, assim, submetê-la à ordenação do Estado.

A liberdade de culto, por sua vez, diz respeito à expressão de crença e de descrença em relação a uma perspectiva, filosofia, ou qualquer outro posicionamento espiritual garantindo, ainda, o efetivo exercício de uma religião. Aqui, José Afonso da Silva atesta que

\footnotetext{
A religião não é apenas sentimento sagrado puro. Não se realiza na simples contemplação do ente sagrado, não é simples adoração a Deus. Ao contrário, ao lado de um corpo de doutrina, sua característica básica se exterioriza na prática dos ritos, no culto, com suas cerimônias, manifestações, reuniões, fidelidades aos hábitos, às tradições, na forma indicada pela religião escolhida. (SILVA, 2007, p. 249).
} 
Destacando a questão da tradição, é válido dizer que a expressão do culto pode se dar de forma individual ou coletiva, uma vez que certas apropriações de uma fé podem ser comuns a grupos de pessoas. Também por esse motivo, ao contrário da liberdade de crença, que se refere ao foro íntimo do indivíduo, a liberdade de culto é tratada como foro externo pela Carta de 1988, conforme disposto em seu artigo $5^{\circ}$, inciso VI. Dessa forma, a liberdade de culto submete-se à ordenação do Estado. A esse respeito, destaca-se que

\begin{abstract}
Por um lado, em o Estado permitir ou propiciar a quem seguir determinada religião o cumprimento dos deveres que dela decorrem (em matéria de culto, de família ou de ensino, por exemplo) em termos razoáveis. E consiste por outro lado (e sem que haja qualquer contradição) em o Estado não impor ou não garantir com as leis o cumprimento desses deveres (MIRANDA, 1993, p. 359).
\end{abstract}

Finalmente, a Constituição brasileira assegura aos cidadãos a liberdade de organização religiosa, por meio da qual é permitido organizar e estabelecer o exercício da religião por meio de instituições. A laicidade do Estado brasileiro fica evidente aqui, pois esse caráter, atrelado à liberdade de organização religiosa, garante que qualquer crença, culto, igreja, assim como os seus representantes, não se vinculam ao Estado.

Conforme disposto no artigo 19 da Constituição:

É vedado à União, aos Estados, ao Distrito Federal e aos Municípios: I - estabelecer cultos religiosos ou igrejas, subvencioná-los, embaraçar-lhes o funcionamento ou manter com eles ou seus representantes, relações de dependência ou aliança, ressalvada, na forma da lei, a colaboração de interesse público (CONSTITUIÇÃO DA REPÚBLICA FEDERATIVA DO BRASIL, 1988).

Do artigo acima infere-se que o Estado tem o dever de reconhecer a personalidade jurídica das instituições religiosas, presumindo que cada religião é responsável por sua organização e regulação, não sendo, portanto, de responsabilidade estatal regê-las.

Ante o exposto, observa-se que a laicidade do Estado brasileiro engloba a liberdade religiosa em três âmbitos distintos: a liberdade de crença, a liberdade de culto e a liberdade de organização religiosa, de modo que, à exceção da organização necessária à manifestação pública dos cultos, as religiões são autônomas perante o Estado. Assim, fica estabelecido que os indivíduos podem professar ou não as crenças com que se identificam, sem nenhum grau de interferência do Estado.

Tendo em conta a explanação acerca das liberdades e valores associados à religião, o quadro abaixo analisa o caminho da tratativa da liberdade religiosa pelas sete Cartas constitucionais brasileiras: 


\section{A LIBERDADE RELIGIOSA NA JURISPRUDÊNCIA BRASILEIRA}

O primeiro exemplo que o artigo apresenta é o da ação civil pública ${ }^{1}$ movida pelo Ministério Público Federal, o Instituto Nacional de Tradição e Cultura Afro Brasileira (INTECAB) e o Centro de Estudos das Relações de Trabalho e da Desigualdade (CEERT), contra a Rede Record de Televisão, a Rede Mulher de Televisão e a União Federal no ano de 2004. Trata-se de um pedido de antecipação de tutela para garantia do exercício de direito de resposta coletivo em virtude menções ofensivas às RMAB veiculadas no programa "Mistérios", em um quadro denominado "Sessão de Descarrego", no ano de 2003.

Os autores da ação acusaram ambas as emissoras de, nesse programa, referir-se constantemente de maneira ofensiva e discriminatória às religiões afro-brasileiras, valendo-se de termos como "encosto", "demônios", "espíritos imundos", "pai de encosto", "mãe de encosto", "bruxaria", "feitiçaria", "sessão de descarrego", sempre atrelados à "macumba" e outros relativos às religiões de matriz africana (MINISTÉRIO PÚBLICO FEDERAL, AÇÃO CIVIL PÚBLICA, 2004).

Segundo atesta a ação civil pública, o embasamento para tal tratamento em relação às RMAB é o livro de autoria do bispo Edir Macedo, "Orixás, Caboclos \& Guias - Deuses ou Demônios”, para quem “dentro da Umbanda, Quimbanda, Candomblé, enfim, de todas as formas de espiritismo, as pessoas são possessas”, ou seja, haveria demonização das religiões afro, conforme destacam os procuradores na ação.

A fundamentação redigida pelo Ministério Público Federal incluiu a seguinte observação: "o que hoje se vê é a invasão dos meios de comunicação em massa, com a exibição de diversas cenas de pastores das chamadas igrejas neopentecostais, efetuando suas pregações em detrimento de outras religiões, com especial enfoque para as de matriz afro-brasileiras" (MINISTÉRIO PÚBLICO FEDERAL, AÇÃO CIVIL PÚBLICA, 2004, p. 9).

Ainda, a ação civil pública chama a atenção para o fato de que as emissoras citadas, em específico, fomentam a discriminação religiosa:

\footnotetext{
Ressaltamos que as emissoras supracitadas reiteradamente e por longo lapso temporal abrem espaço em suas programações para que representantes de determinadas religiões depreciem as de matriz africana, quer proferindo metáforas que mal disfarçam o endereçamento das ofensas, quer induzindo diretamente à discriminação e ao preconceito, fazendo com que a população seja acometida em seus lares por práticas abusivas, tendo seus direitos sociais e individuais indisponíveis lesados (MINISTÉRIO PÚBLICO FEDERAL, AÇÃO CIVIL PÚBLICA, 2004, p. 9).
} 
Em resposta aos ofícios enviados, a Rede Mulher declarou que "não há durante os programas exibidos na emissora assunto algum relacionado à religião, qualquer que seja - exceção feita aos programas exibidos durante a noite" (MINISTÉRIO PÚBLICO FEDERAL, AÇÃO CIVIL PÚBLICA, 2004, p. 5), e que não há possibilidade de alteração da programação já estipulada para que temas distintos sejam incluídos.

A resposta da Rede Record, por sua vez, alegou que "caso as entidades interessadas na presente Representação desejem condições comerciais isonômicas àquelas praticadas com as demais entidades religiosas, certamente tal tratamento lhes será assegurado" (MINISTÉRIO PÚBLICO FEDERAL, AÇÃO CIVIL PÚBLICA, 2004, p. 5), argumentando ainda que o direito de resposta gratuito requerido não encontra espaço na dinâmica comercial televisiva.

A decisão, proferida em 15 de dezembro de 2014 pelo juiz Djalma Moreira Gomes, de São Paulo, condenou as emissoras a veicular durante 30 dias consecutivos programas com duração de duas horas, dedicados às respostas das associações autoras da ação, determinando ainda que lhes fossem concedidos espaço e funcionários para a gravação dos programas. Ainda, foi estipulada multa de 500 mil reais para cada dia de descumprimento da sentença (SÃO PAULO, JUSTIÇA FEDERAL, Sentença Tipo A, 2014, pp. 1-2). A União Federal foi excluída da decisão, em vista da impossibilidade jurídica de conceder direito de resposta.

O magistrado fundamentou a sua decisão ante o fato de que as empresas de radiodifusão são longa manus do Estado, de modo que, assim como o Estado, "devem se comportar no cumprimento das regras e princípios constitucionais legais". Com isso, cabe às emissoras garantir as premissas constitucionais de "promoção do bem de todos, sem preconceito de origem, raça, sexo, cor, idade e quaisquer outras formas de discriminação", e também o "pleno exercício dos direitos culturais, protegendo as manifestações das culturas populares, indígenas e afro-brasileiras" ${ }^{2}$, ressaltado também o fato de que, "em caso de ofensa, é assegurado o direito de resposta, proporcional ao agravo" (SÃO PAULO, JUSTIÇA FEDERAL, Sentença Tipo A, 2014, pp. 15-21).

O segundo caso que esta pesquisa toma como exemplo é a ação civil pública ${ }^{3}$ movida pelo Ministério Público Federal, no ano de 2014, em resposta à manifestação da Associação Nacional de Mídia Afro (ANMA), de que grupos evangélicos postaram na plataforma Youtube vídeos de conteúdo ofensivo e discriminatório em relação às RMAB. A ação movida pelo Ministério Público é de autoria de Márcio de Jagun, advogado carioca e babalorixá de Candomblé.

Originalmente, a ação foi movida contra a Mitra Episcopal do Rio de Janeiro e o Google Brasil, proprietária da plataforma Youtube. Entretanto, a decisão foi emitida tendo como ré somente 
a empresa de internet, que, em sua defesa, alegou estar prestando serviços à liberdade de opinião e de expressão.

A notoriedade desse caso se deveu à decisão proferida pelo juiz Eugênio Rosa de Araújo, da $17^{\text {a }}$ Vara Federal do Rio de Janeiro, proferida em 28 de abril de 2014. Na opinião do magistrado, os vídeos postados pelos grupos evangélicos não podem ser caracterizados como desrespeito à liberdade de religião, de culto e de reunião, pois os cultos afro-brasileiros (expressão adotada pelo juiz para se referir às $\mathrm{RMAB}$ ) "não contêm os traços necessários de uma religião a saber, um texto base (corão, bíblia, etc.) ausência de estrutura hierárquica e ausência de um Deus a ser venerado" (RIO DE JANEIRO, JUSTIÇA FEDERAL, Decisão, 2014, p. 3, folha 154).

O teor da decisão do magistrado carioca se assenta na sua percepção pessoal de que as RMAB não são religiões nem sistemas de fé. Com efeito, foi declarado na decisão que

Para o exame da tutela, não se apresenta malferimento de um sistema de fé. As manifestações religiosas afro-brasileiras não se constituem em religiões, muito menos os vídeos contidos no Google refletem um sistema de crença - são de mau gosto, mas são manifestações de livre expressão de opinião. Quanto ao aspecto do direito fundamental de reunião, os vídeos, bem como os cultos afro-brasileiros, não compõem uma vedação à continuidade da existência de reuniões de macumba, umbanda, candomblé ou quimbanda (RIO DE JANEIRO, JUSTIÇA FEDERAL, Decisão, 2014, p. 3, folha 154).

O juiz atestou ainda que os vídeos veiculados no Youtube em nada restringem a prática dos "cultos afro-brasileiros".

O Ministério Público Federal recorreu da decisão em maio de 2014, amparando a argumentação principalmente na incolumidade da consciência religiosa e na percepção de que "que há limites para as manifestações religiosas. Ninguém, a pretexto de manifestar sua fé, está autorizado a atacar ou ofender, exatamente porque a liberdade de manifestação religiosa também não é absoluta" (RIO DE JANEIRO, MINISTÉRIO PÚBLICO FEDERAL, Agravo de Instrumento, 2014, p. 17).

A decisão do juiz Eugênio Rosa de Araújo teve ampla repercussão e foi alvo de inúmeras críticas, inclusive de lideranças católicas e evangélicas. Com efeito, o frei franciscano David Raimundo dos Santos considerou que faltou ao magistrado conhecimento das religiões afrobrasileiras: "a definição de religião que o juiz tem na cabeça revela total desconhecimento das teses teológicas. [...] Caso os membros das religiões afro façam protestos, terão o apoio de nós, católicos" (DECISÃO..., c2014). Em consonância, o pastor batista Henrique Vieira considera que "essa decisão desrespeita a identidade cultural e religiosa que é legítima. É uma violência que se dá no âmbito do discurso" (DECISÃO..., c2014), e apoia manifestações em protesto ao entendimento do juiz. 
Em 20 de maio e 2014, ou seja, menos de um mês após a polêmica decisão, o magistrado reconsiderou os seus termos, alegando que

O forte apoio dado pela mídia e pela sociedade civil, demonstra, por si só, e de forma inquestionável, a crença no culto de tais religiões, daí porque faço a devida adequação argumentativa para registrar a percepção deste Juízo de se tratarem os cultos afrobrasileiros de religiões, eis que suas liturgias, deidade e texto base são elementos que podem se cristalizar, de forma nem sempre homogênea (RIO DE JANEIRO, JUSTIÇA FEDERAL, Conclusão, 2014).

Entretanto, foi mantida a veiculação dos vídeos, objeto central da ação, no Youtube, decisão revogada pelo desembargador Reis Friede, do Tribunal Regional Federal da $2^{\mathrm{a}}$ região, em junho de 2014. Em caráter liminar, foi estipulado o prazo de 72 horas para que a Google Brasil retirasse do ar os vídeos apontados como ofensivos e discriminatórios em relação às RMAB, bem como multa diária de 50 mil reais em caso de descumprimento.

O desembargador sustentou em sua decisão que

\begin{abstract}
Deve-se registrar, desde logo, que o direito de praticar livremente uma religião não inclui a liberdade para expor indivíduos de outras religiões a ofensas. [...] A cada dia em que os vídeos permanecem disponíveis no site Youtube, perpetuam-se as mensagens de ódio, discriminação, intolerância e violência neles contidas, que continuam sendo disseminadas a um número indeterminado de pessoas, tendo em vista o acesso irrestrito a tal conteúdo (TRF..., c2014).
\end{abstract}

De fato, após a decisão do juiz Eugênio Rosa, líderes do Candomblé e Umbanda alegaram temer atos de violência, uma vez que, ao não considerar as RMAB como religiões, o próprio juiz "acaba expressando uma opinião parecida com quem prega o ódio" (LÍDERES..., c2014).

As críticas à decisão também partiram do âmbito jurídico, como ilustra a percepção do jurista Alexandre Aragão, para quem "não cabe a um juiz diminuir a proteção que a constituição dá a todas as expressões religiosas. Ao reduzir o conceito de religião a apenas três religiões [...] monoteístas, ela deixa desprotegida uma grande parcela de expressões religiosas que a constituição protege sim" (LÍDERES..., c2014).

A Rede Record e a Igreja Universal do Reino de Deus recorreram da sentença, e o recurso foi julgado em 5 de abril de 2018 pelo Tribunal Regional Federal de São Paulo. O julgamento foi conduzido pela desembargadora Consuelo Yoshida, que votou pelo indeferimento do recurso, e foi acompanhada pelos dois outros magistrados presentes (RECORD..., c2018).

É importante ressaltar aqui que o julgamento da ADI 4439 envolveu a realização de audiência pública em junho de 2015, em que instituições religiosas e culturais manifestaram as suas percepções. 
A título de exemplo, estiveram presentes a Federação Nacional do Culto Afro-Brasileiro e da Federação de Umbanda e Candomblé de Brasília e Entorno. Ambas as instituições sustentaram a necessidade de o Conselho Nacional de Educação elaborar diretrizes curriculares relativas ao ensino religioso, no sentido de que todas as religiões sejam contempladas, inclusive as de matriz africana e indígena. Afirmaram ainda que o ensino religioso vigente no país atualmente não engloba adequadamente as RMAB, defendendo a necessidade de criar cursos de licenciatura nas instituições de ensino superior que contemplem todas as crenças (STF, 2015).

A Igreja Universal do Reino de Deus, por sua vez, defendeu que o ensino confessional deve estar condicionado à presença de docentes qualificados nesse sentido, pois "o ensino deve ser sobre religião, e não da religião" (STF, 2015). O representante dessa instituição argumentou ainda que o ensino religioso deve ser ministrado de modo a contemplar "balizas como a maior laicidade possível, a dimensão cultural da religião, o caráter instrumental do ensino religioso, que deve estar a serviço da educação pública, e o quadro docente laico" (STF, 2015).

Em termos de repercussão da decisão do STF, as opiniões são diversas, com espaço para muitos questionamentos. A título de exemplo, o docente do departamento de Teologia e Ciências da Religião da PUC-SP, Jorge Cláudio Ribeiro, considera se tratar de uma decisão prejudicial, uma vez que parece "haver uma contradição entre uma disciplina que é optativa e que ao mesmo tempo é confessional, ou seja, é optativa para os alunos e obrigatória para uma religião só" (DECISÃO..., c2017).

Ainda, o docente manifestou preocupação no sentido de o espaço dedicado às RMAB diminua a ponto de silenciar as referências ao Candomblé e Umbanda, por exemplo, sustentando que "seria lamentável que a guerra religiosa que existe em alguns nichos bastante difundidos da sociedade fosse transportada para as escolas [...]. É preciso que a comunidade escolar seja capaz de criar um ambiente de convivência" (DECISÃO..., c2017).

Cumprida a proposta de explorar casos em que a jurisprudência brasileira se manifestou em relação à temática religiosa, após refletir acerca do processo legislativo e de elementos da tradição nacional, o trabalho segue para as considerações finais permitidas pelo desenvolvimento da pesquisa.

\section{CONSIDERAÇÕES FINAIS:}

O presente artigo tomou como objeto de estudo a liberdade religiosa, estipulando um recorte de modo a englobar a tratativa deste tema no âmbito das religiões de matriz afro-brasileira. 
Assumiu-se como hipótese que a premissa de liberdade religiosa expressa na legislação brasileira, permeada também pela liberdade de culto, de crença e de consciência é relativizada na dinâmica social, cultural e política do Brasil, o que permite ainda uma reflexão a respeito da real amplitude da atestada laicidade do Estado brasileiro.

Para tanto, o desenvolvimento da pesquisa partiu, em seu primeiro capítulo, da análise da colonização brasileira, permitindo estabelecer que a Igreja Católica, apesar de ter desempenhado papel fundamental na formação do Brasil, deixou uma herança religiosa que permeia vários setores e aspectos da realidade brasileira, inclusive no âmbito jurídico. Por esse motivo, propôs-se uma abordagem histórica das sete Constituições que já vigoraram no Brasil, destacando em cada uma o tratamento dedicado à temática religiosa.

$\mathrm{Na}$ esteira dessa constatação, o segundo capítulo do trabalho se dedicou a estudar a laicidade, enquanto conceito e valor instituído no texto constitucional brasileiro vigente. Em um primeiro momento foi feita a diferenciação entre laicidade e laicismo, para, em seguida, tratar de conceitos como liberdade de culto, consciência e de crença, que devem estar obrigatoriamente presentes quando se trata da separação entre Estado e religião.

Em complemento, refletiu-se acerca de valores como tolerância e alteridade, também fundamentais às premissas de liberdade religiosa e laicidade, tendo em conta que a diversidade cultural e religiosa traz consigo a necessidade de convivência com o "diferente", além da percepção de que não há nem pode haver um determinado valor, costume ou preceito superior aos demais.

Em consonância com o exposto na primeira etapa do trabalho, o terceiro capítulo cuidou do sincretismo religioso, da diversidade religiosa e cultural permitida pela herança dos nativos indígenas, bem como pela chegada dos escravos africanos ao Brasil. Aqui, feita a reflexão acerca da fundamental importância da herança indígena e africana para o Brasil, o trabalho dedicou espaço à apresentação da lei 10.639/2003, que, além de atestar a obrigatoriedade do ensino das raízes africanas brasileiras, permitiu o reconhecimento da existência do racismo no Brasil, inclusive no âmbito das escolas.

Por fim, o último capítulo do trabalho cuidou da análise do processo legislativo brasileiro acerca da temática religiosa, articulada à análise de alguns elementos da tradição brasileira que remetem à religião. Em seguida, no intuito de ilustrar a complexidade da relação entre cultura, religião, legislação e dinâmica estatal, foram apresentados três casos de jurisprudência relativos a questões religiosas, todos eles com multiplicidade de atores, valores e percepções.

A exploração bibliográfica e levantamento de dados e casos realizados para a confecção dessa pesquisa permitiram a observação de que a proposta de laicidade do Estado, apesar de ser 
uma percepção amplamente difundida, inclusive em âmbito internacional, ainda carece de reflexão e amadurecimento jurídico e legislativo, o que reflete diretamente na postura do Estado perante a temática religiosa. Isso se deve ao fato de que os legisladores e operadores do Judiciário, sendo indivíduos com valores e perspectivas próprias, por vezes envolvem a tratativa da religião e da lei segundo suas percepções pessoais.

Faz-se necessária também maior participação popular nas decisões que envolvem questões religiosas. Entretanto, trata-se também de uma via complexa, haja vista a tradição brasileira trazer tantos elementos cristãos, evidentemente herança da colonização portuguesa católica. Nesse sentido, a tendência é que seja criada uma percepção, ainda que ilusória, que os grupos que professam o cristianismo, por estarem em maioria numérica, podem "guiar" a dinâmica social, cultural e política brasileira segundo as suas convicções.

Soma-se a essa percepção a constatação de que o ensino e difusão da herança indígena e afro, evidentemente fundamentais à sociedade brasileira não apenas pelos fatos históricos, mas também pela sua própria composição, majoritariamente negra e parda, não possuem a mesma amplitude do ensino das religiões cristãs. Esse cenário leva a decisões equivocadas e inaceitáveis como a do juiz carioca Eugênio Rosa de Araújo, que, ao considerar que as RMAB não são religiões, demonstrou não apenas falta de conhecimento acerca da herança do seu próprio país, mas também estabeleceu um cenário de hierarquia entre as religiões monoteístas e as de matriz africana, o que fomenta o preconceito e hostilidade em relação a esses rótulos religiosos.

Essa realidade de ofensa, hostilidade e desqualificação das RMAB é sustentada pela veiculação de opiniões de determinados grupos, notadamente pela internet. Foi possível refletir a respeito desse cenário por meio da apresentação do caso em que a Rede Record e Rede Mulher foram condenadas a conceder direito de resposta a instituições dedicadas à representação das RMAB, após a transmissão de programas que ofendiam e tratavam de maneira hostil e pejorativa as crenças afro-brasileiras.

Entretanto, apesar de esse caso ser incontestavelmente uma vitória para a defesa da diversidade cultural e religiosa, cabe destacar aqui que a sentença foi proferida em 2014, dez anos após a interposição da ação civil pública. Evidencia-se, então, que a demora em solucionar essa lide abriu espaço para que o desrespeito nas emissoras de televisão e internet às RMAB perdurassem, pois ainda não havia um precedente em termos de jurisprudência que condenasse esse tipo de prática.

Por fim, a recente decisão do STF a respeito do ensino confessional nas escolas, apesar de estar em consonância com o disposto na Constituição Federal e em nenhum momento incitar a 
primazia cristã ou desqualificar a diversidade religiosa e cultural, traz à tona questionamentos acerca da real possibilidade de as RMAB serem contempladas no ensino religioso das escolas, principalmente as públicas, bem como no que diz respeito à obrigatoriedade do ensino da herança negra e indígena estabelecida pela lei 10.639/2003.

Trata-se, aqui, de uma reflexão no sentido de o ensino confessional ser predominantemente cristão, haja vista a maior parte da população se declarar cristã, além dos inúmeros episódios de preconceito e menosprezo em relação às RMAB. Com isso, existe a possibilidade de que o ensino confessional, devidamente regulamentado pela legislação, diminua o espaço que as RMAB ainda se esforçam para conquistar.

Dessa forma, a pesquisa considera que a premissa do Estado laico e a tratativa da liberdade religiosa ainda têm de primeiramente reconhecer sua própria complexidade para, então, tratar dos obstáculos e questionamentos que se apresentarem tendo sempre em conta a riqueza e pluralidade histórica, cultural e religiosa da sociedade brasileira.

\section{REFERÊNCIAS:}

ABBAGNANO, Nicola. Dicionário de Filosofia. $3^{a}$ ed. São Paulo: Martins Fontes, 1998.

BASTOS, Celso Ribeiro. Curso de Direito Constitucional. São Paulo: Celso Bastos Editora, 2002.

BOBBIO, Norberto. Igualdade e Liberdade. $5^{\text {a }}$ ed. Rio de Janeiro: Ediouro, 2002.

BONAVIDES, Paulo. Curso de Direito Constitucional. 24a ed. São Paulo: Editora Malheiros, 2009.

BRASIL. Constituição da República Federativa do Brasil. Coleção Legislação da Editora Saraiva. São Paulo: Saraiva, 2010.

BRASIL. LEI N. 10.639, de 9 de janeiro de 2003. Altera a Lei no 9.394, de 20 de dezembro de 1996, que estabelece as diretrizes e bases da educação nacional, para incluir no currículo oficial da Rede de Ensino a obrigatoriedade da temática "História e Cultura Afro-Brasileira", e dá outras providências. Disponível em: <http://www.planalto.gov.br/ccivil_03/leis/2003/110.639.htm>. Acesso em 16/nov/2017.

CASTRO, Eduardo Viveiros de. O mármore e a murta: sobre a inconstância da alma selvagem. In: CASTRO, E. V. A inconstância da alma selvagem. São Paulo: Cosac Naify, 2002.

CAVALCANTI, Themístocles Brandão; BRITO, Luís Navarro, BALEEIRIO, Aliomar. Coleção Constituições Brasileiras - 1967. v.5. 3. ed. Brasília: Senado Federal, Subsecretaria de Edições Técnicas, 2012.

CINTRA, Jorge Pimentel. Reconstruindo o Mapa das Capitanias Hereditárias. Anais do Museu Paulista. São Paulo; v.21. n.2. p. 11-45. Jul-dez. 2013. 
CONSELHO DE MAGISTRATURA DO TRIBUNAL DE JUSTIÇA DO RIO GRANDE DO SUL. Processo n 0139-11/ 000348-0. 2012. Relator Desembargador Cláudio Baldino Maciel. Interessados: Rede Feminista de Saúde, SOMOS - Comunicação Saúde e Sociedade, NUANCES Grupo pela Livre Orientação Sexual, Liga Brasileira de Lésbicas, Marcha Mundial de Mulheres, THEMIS - Assessoria Jurídica e Estudos de Gênero. Disponível em:

http://www.cnj.jus.br/dje/jsp/dje/DownloadDeDiario.jsp?dj=DJ107_2016-

ASSINADO.PDF\&statusDoDiario=ASSINADO

FAUSTO, Boris. História do Brasil: História do Brasil cobre um período de mais de quinhentos anos, desde as raízes da colonização portuguesa até nossos dias. São Paulo: EDUsp, 1996.

FERRETTI, Sérgio E. Sincretismo Afro-Brasileiro e Resistência Cultural. Revista Horizontes Antropológicos. Porto Alegre, ano 4, n. 8, p. 182-198, jun. 1998.

FONSECA, Dagoberto José. Diversidade Cultural e Educação: apontamentos necessários. Cadernos de Formação. São Paulo: UNESP, v. 01, p. 51-63, 2003.

FREYRE, Gilberto. Casa-grande e Senzala: formação da família brasileira sob o regime da economia patriarcal. 49a ed. São Paulo: Global, 1992.

KELSEN, Hans. Teoria Geral do Direito e do Estado. $3^{\text {a }}$ ed. São Paulo: Editora Martins Fontes, 1998.

LENINE, Helton. Quando a política e religião se misturam. DM, 15/nov/2015. Disponível em: < https://www.dm.com.br/politica/2015/11/quando-a-politica-e-religiao-se-misturam.html $>$. Acesso em 15/nov/2017.

LOPES, Fabio Almeida. Princípios do processo legislativo: uma perspectiva interdisciplinar e sistêmica. Monografia (especialização) - Centro de Formação, Treinamento e Aperfeiçoamento (Cefor), da Câmara dos Deputados, Curso de Especialização em Processo Legislativo. Brasília, 2009.

MACEDO, Emiliano Unzer. Religiosidade popular brasileira colonial: um retrato sincrético. Revista Ágora. Vitória - ES, n. 7, 2008, p.1-20.

MACEDO, Fausto. Procurador insiste na retirada de símbolos religiosos de repartições públicas. O Estado de São Paulo, 13/jan/2013. Disponível em:

$<$ http://politica.estadao.com.br/noticias/geral,procurador-insiste-na-retirada-de-simbolos-religiososde-reparticoes-publicas,991391>. Acesso em 16/nov/2017.

MELlO, Celso Antônio Bandeira. O Conteúdo Jurídico do Princípio da Igualdade. $3^{\text {a }}$ ed. São Paulo: Editora Malheiros, 2006.

MENESES, Paulo. Filosofia e Tolerância. Revista Síntese Nova Fase, Belo Horizonte, v. 23, n. 72, 1996.

MORAES, José Geraldo Vinci de. História Geral e do Brasil. São Paulo: Atual, 2003. 
ORDEM DOS ADVOGADOS DO BRASIL. Liberdade Religiosa: conceitos. São Paulo: Editora Luz, 2011.

RAMOS, Elival da Silva. Notas sobre a liberdade de religião no Brasil e nos Estados Unidos. Revista da Procuradoria Geral do Estado de São Paulo. São Paulo, n. 27-28, p. 199-246. Jan/Dez de 1987.

RIO DE JANEIRO, JUSTIÇA FEDERAL, Conclusão, 2014. AÇÃO CIVIL PÚBLICA Processo $\mathbf{n}^{0}$ 0004747-33.2014.4.02.5101 (2014.51.01.004747-2). Juiz Federal Eugênio Rosa de Araújo. 17 Vara Federal do Rio de Janeiro. Disponível em: $<$ https://www.conjur.com.br/dl/decisao-negouretirada-videos.pdf $>$. Acesso em 20/nov/2017.

RIOS, José Arthur. Sentimento religioso no Brasil. In: HORTA, Luiz Paulo. Sagrado e profano. Rio de Janeiro: Editora Agir, 1994.

ROUSSEAU, Jean-Jaques. Do contrato social ou princípios do direito político. Trad. de Pietro Nassetti. São Paulo: Martin Claret, 2003.

SAMPAIO, Dilaine Soares. As manifestações de religiosidade não contém traços necessários de uma religião: uma análise das relações entre Poder Judiciário e religiões afro-brasileiras. Dossiê Religiões Afrobrasileiras. Caicó, v. 15, n. 34, p. 54-82, jan./jun. 2014. Disponível em: $<$ https://periodicos.ufrn.br/mneme/article/viewFile/7105/5542>. Acesso em 21/nov/2017.

SANTOS JÚNIOR, Aloísio Cristovam. A liberdade de organização religiosa e o Estado laico brasileiro. São Paulo: Mackenzie, 2007.

SARMENTO, Daniel. Direitos fundamentais nas relações privadas. Rio de Janeiro: Editora Lumen Juris, 2004.

SANTOS JÚNIOR, Aloísio Cristovam. O Crucifixo nos Tribunais e a Laicidade do Estado. Revista Eletrônica PRPE. P. 1-17. Maio de 2007.

SECAD. Orientações e Ações para a Educação das Relações Étnico-Raciais. Brasília:

Ministério da Educação, Secretaria de Educação Continuada, Alfabetização e Diversidade, 2006.

SENADO FEDERAL BRASILEIRO. Jornal da Constituinte - Exposição "A Participação Popular nos 25 anos da Constituição Cidadã". Brasília, de 29 de outubro a 8 de novembro de 2013.

Disponível em: $<$ http://www.senado.leg.br/noticias/especiais/constituicao25anos/exposicao-senadogaleria/Jornal-Constituinte.pdf $>$. Acesso em 20/nov/2017.

SILVA, Helder Kuiawinski da. A Cultura Afro como Norteadora da Cultura Brasileira. Revista Perspectiva. Erechim. v. 38, n.144, p. 25-35, dezembro/2014.

SILVA, Vagner Gonçalves. Intolerância religiosa: impactos do neopentecostalismo no campo religioso afro-brasileiro. São Paulo: Editora da Universidade de São Paulo, 2007.

VAINER, Bruno Zilberman. Breve Histórico Acerca das Constituições do Brasil e do Controle de Constitucionalidade Brasileiro. Revista Brasileira de Direito Constitucional, n. 16 - jul./dez. 2010, p. 161-191. 


\section{NOTAS:}

${ }^{1}$ Processo n. 2004.61.00.034549-6, de 2004.

${ }^{2}$ Grifos nossos.

${ }^{3}$ Processo no $0004747-33.2014 .4 .02 .5101$.

\section{AUTORES:}

\section{Otávio Barduzzi Rodrigues da Costa}

Sociólogo pela UNESP--, Advogado - ITE. Mestre em filosofia pela UNESP. Doutorando em Ciências sociais UNESP. Professor de Antropologia e Sociologia da Universidade Anhanguera. Bolsista Cnpq.

\section{Luiz Fernando de Lima Ribeiro}

Bacharel em Direito UNIESP.

\section{Roberta Cava}

Bacharel em relações internacionais UNESP. Mestra em Ciência Política pela UFSCAR. Doutoranda em Ciências sociais UNESP. 